\title{
Assessment of Breast Aesthetics
}

\author{
Min Soon Kim ${ }^{1}$, Juliano C. Sbalchiero ${ }^{2}$, Gregory P. Reece ${ }^{3}$, Michael J. Miller ${ }^{3}$, Elisabeth K. \\ Beahm $^{3}$, and Mia K. Markey ${ }^{1}$ \\ ${ }^{1}$ Biomedical Engineering Department, The University of Texas at Austin \\ 2 Plastic Surgery and Microsurgery Department of INCA (National Cancer Institute) and Plastic \\ Surgery Department of Clementino Fraga Filho Hospital at Federal University of Rio de Janeiro - \\ Brazil
}

${ }^{3}$ Plastic Surgery Department, The University of Texas M. D. Anderson Cancer Center

\begin{abstract}
A good aesthetic outcome is an important endpoint of breast cancer treatment. Subjective ratings, direct physical measurements, measurements on photographs, and assessment by threedimensional imaging are reviewed and future directions in aesthetic outcome measurements are discussed. Qualitative, subjective scales have frequently been used to assess aesthetic outcomes following breast cancer treatment. However, none of these scales has achieved widespread use because they are typically vague and have low intra- and inter- observer agreement.

Anthropometry is not routinely performed because it is impractical to conduct the large studies needed to validate anthropometric measures, i.e., studies in which several observers measure the same subjects multiple times. Quantitative measures based on digital/digitized photographs have yielded acceptable results but have some limitations. Three-dimensional imaging has the potential to enable consistent, objective assessment of breast appearance, including properties, such as volume, that are not available from two-dimensional images. However, further work is needed to define 3D measures of aesthetic properties and how they should be interpreted.
\end{abstract}

\section{Keywords}

Aesthetics; Breast Neoplasm; Esthetics; Mastectomy; Outcomes; Prostheses and Implants; Reconstructive Surgical Procedures; Surgical Flaps; Treatment Outcome; Quality of Life; Breast Conservation Therapy

\begin{abstract}
The goal of plastic surgery of the breast is to recreate a natural appearance that is satisfying to the patient. Despite the fundamental nature of this outcome, breast aesthetics is poorly understood and difficult to measure. In this context, aesthetics refers to physical characteristics of the breast that determine the subjective evaluation of appearance (1). Although factors such as breast size, shape, and proportion (2-6) are generally understood to be important, there remains no objective, quantifiable determinants of breast aesthetics that are universally acknowledged (7). This absence of standards makes it difficult to compare outcomes of different surgical techniques. It also fosters discord when a discrepancy exists between the aesthetic impression of the plastic surgeon and the patient. Patients and plastic surgeons can have significantly different perceptions of body image regarding attractiveness, natural, and ideal breast shape $(8,9)$. The relationship between physical appearance and psychological body image is a central aspect of a patient's quality of life, and study of this
\end{abstract}

Corresponding Author Contact Information Mia K. Markey, Ph.D. 1 University Station C0800 Biomedical Engineering ENS 617B The University of Texas at Austin Austin, TX 78712+1.512.471.1711+1.512.471.0616 (fax) mia.markey@mail.utexas.edu. 
relationship requires appropriate aesthetic outcome assessment (10-15). It is essential to characterize the elements of aesthetic breast appearance in order to make meaningful comparisons between competing surgical techniques, to adequately inform patients of realistic outcomes, and to make systematic advances in treatment. In addition, objective measures are crucial for documenting to third party payers and health policy analysts the clinical value of costly techniques such as autologous breast reconstruction $(6,16,17)$.

This article critically reviews current approaches to breast aesthetic measurements: subjective assessments by human observers, measurements on the patient's body (anthropometry), measurements on photographs (photogrammetry), and measurements using three-dimensional images of the breasts.

\section{Subjective Ratings}

Typically, visual assessment of breast aesthetics is reported using a crude gradation scale that is inherently subjective and qualitative (Table 1). Substantial variability has been reported in the use of common scales of four gradations of cosmetic change $(\kappa=0.21-$ $0.31)(18,19)$. Likewise, the reported reliability of visual analogue scales is unacceptable $(\kappa$ $=0.13-0.15)(19)$.

It has been argued that global scales suffer from vague terminology and that more reliable aesthetic assessments will require separate measurements of individual factors. Subscales with more explicit criteria for each aesthetic component (e.g., volume) have been recommended (19), but substantial observer variability was still reported $(\kappa=0.19-0.63)$ (19). Similarly, subscales of four gradations have been proposed for rating the difference between treated and untreated breasts in terms of size, shape, skin color and firmness, and the visibility of surgical scar, but the reliability was low to moderate $(\kappa=0.24-0.40)$ (20).

It is also noteworthy that there is a lack of concordance between different observer groups (21-23). Sneeuw et al. reported that patients demonstrated significantly greater variation $(\kappa<$ $0.10)$ in aesthetic scoring compared to professionals $(\kappa=0.64)$ using 4-point subscales $(20)$. In contrast, a study by Cohen $e$ al., which employed a global 5-point scale, reported greater internal consistency among patients (Chronbach $\alpha=0.92)$ compared to medical professionals (Chronbach $\alpha=0.74-0.89$ ). There was poor inter-observer agreement among surgeons $(\kappa=0.0-0.39)$ and a weak correlation between surgeons and patients (Spearman $\rho$ $=0.36-0.53)(24)$.

These studies highlight two major disadvantages of subjective scales. The first is variable internal consistency and reproducibility as demonstrated by low intra- and inter- observer agreement (Table 1). Consequently, data averaged from a panel rather than individual evaluators are often employed, but this approach is time and labor intensive and can reduce variability but not improve accuracy. The second problem is the lack of a standardized, explicit scale for analyzing cosmetic outcome. A crude ordinal scale with four or five categories is imprecise for identifying individual aesthetic elements.

\section{Physical Measurements}

Anthropometry is based on linear measurements between surface landmarks (Table 2). Penn's approach of defining nipple-to-sternal notch and midclavicular point distances based on 20 women with "aesthetically perfect" breasts has gained broad attention and has been adopted by some as normative (25). Similarly, the distances between fiducial points were computed in 66 women in whom one-third had either breast hypertrophy, ptosis, or both (26). Another study measured the symmetry of 40 patients by computing differences between the right and left breast and investigated the relationship between subjective ratings 
and linear measurements (27). "Aesthetically perfect breasts" was defined as a breast shape for which no aesthetic procedure would be indicated. The problem with this definition is that different surgeons have different notions of when an aesthetic procedure is indicated. For example, in general, European Plastic Surgeons feel that what American Plastic Surgeons consider to be the "ideal breast" is really too large and they would recommend a breast reduction. Twenty two linear measurements were designed and compared to the results with those of Penn (25) and Smith (26). Nine of the measures were shown to have statistically significant correlation (Pearson $r=0.459-0.592$ ) with breast volume $(28)$.

Symmetry has typically been determined by calculating the difference in measured distances on the breast mound and nipple/areola complex. In the Breast Compliance Evaluation (BCE) method, the distance from the point of mid-clavicle to the inframammary fold through the center of the nipple is measured in both supine and erect positions using a tape measure. Compliance was calculated from controls and cancer patients by determining the difference in the measures between the two positions and the aesthetic outcome of treated breasts was evaluated by comparing the difference between the compliances of the two breasts. Correlation between BCE and satisfactory cosmetic outcomes was reported, but the reliability of the measurement is not clear (29). Combination of physical measurement with subjective ratings was attempted to measure the symmetry by making three measurements on 72 patients with asymmetrical breasts, but the correlation between the measures and reproducibility was not analyzed (30). Areola diameter in addition to the distances between sternal notch-to-nipple, and nipple-to-inframammary fold were measured, and compared with the subjective ratings for patients with developmental asymmetry (31).

Another study computed the distances between the nipple and the borders of the breast to calculate the nipple-areola-breast proportion and showed correlation of patient characteristics and breast proportions. Significant positive linear correlation between age and areola-breast proportion (Pearson $r=0.47$ ) was reported and areola-nipple proportion was shown to be significantly larger in higher ptosis grades (32).

Anthropometry can be a useful tool for quantifying aesthetic outcomes. However, this method has several pragmatic limitations. Fundamental parameters such as breast projection are difficult to evaluate because of the curvature of the underlying chest wall and mobility of subcutaneous tissue. Studies of linear measurements on a patient must be done prospectively and they require an extra intervention, which tends to keep the number of subjects low. It is not feasible to make a large number of measurements on each subject. If a particular measurement doesn't prove valuable, one can't retrospectively try a different one. To prove the validity of a specific measurement, studies across multiple institutions with multiple observers are needed, which are costly. The relationships to subjective scales is unclear (27, $30,31,33,34)$. For these reasons, direct measurements have limited utility in routine clinical practice and are not generally performed.

\section{Photographic Measurements}

The value of photographs for subjective assessment of breast aesthetics is confirmed by comparable results for assessments based on photographs compared to physical examination (35). Prints produced from digital images, digital images displayed on computer monitor, or conventional photographs are acceptable to observers for subjective assessment of breast aesthetics (36).

Rather than simply obtaining subjective ratings based on photographs, several investigators $(35,37-42)$ describe measurements calculated on digital/digitized photographs (Table 3 ). This approach has yielded encouraging results, but there are limitations to the reported studies. The majority of these have only been reported in breast cancer patients undergoing 
breast conservation therapy (BCT) and have limited utility for full aesthetic assessment. They rely on many of the same fiducial points described above for anthropometry, but some anatomical landmarks may not be visible in photographs (e.g., the inframammary fold). They also rely heavily on the anatomy of the nipple/areola complex, which may not reflect independent features of the breast mound. Finally, they typically involve only a single anterior-posterior (AP) photograph for each patient.

Breast Retraction Assessment (BRA) has been successfully applied in the assessment of asymmetry (41). The BRA measure is the Euclidean distance between right and left nipples. Early studies employed the aid of a clear acrylic sheet marked as a grid with the patient behind the screen, which is functionally equivalent to calculating distances on a digitized/ digital photograph. BRA was compared between normal volunteer and 27 BCT patients, and the measure was significantly greater for the breast cancer patients than for the control group. BRA calculations correlated with the size of resection (41).

Van Limbergen et al. $(38,39)$ calculated four measurements on AP photographs: the vertical distance from the level of the sternal notch to the nipple (A), the vertical distance from the level of sternal notch to the inferior pole of the breast (I), the horizontal distance from the midline to the nipple (M), and the horizontal distance from the midline to the lateral breast contour (L). They used the differences in each measure between the left and right breasts as measures of symmetry (e.g., $\Delta \mathrm{I})$. Subjective assessment by a panel comprised of a surgeon, a radiotherapist, and a non-physician was also made from the photographs using a five-point scale and the mean panel rating was correlated to the BRA measure. In 142 BCT patients, significant correlations between BRA and the subjective scores $(p=0.0001$ : X square test, Kendall Tau B and Kendall Tau C) were found, with increased BRA associated with poorer cosmetic outcome. Since the magnification of clinical photographs is not standardized, they introduced a relative version of the BRA measure ( $p$ BRA) equal to BRA divided by the distance from the sternal notch to the nipple of the untreated breast. Using this measure they found smaller intra- and inter- observer variability based on $p$ BRA than on subjective assessments. They also found a significant correlation between $p$ BRA and subjective assessment at a three-year follow-up except for those with inferomedially located tumors ( $\rho$ $=0.24-0.53)(39,40)$ (Figure 1).

Some studies have employed a computer program to obtain more consistent measurements (42). Four measurements were calculated on AP images of 148 women who underwent $\mathrm{BCT}$. Distances were computed for from each nipple to the contralateral nipple, the inferior pole of the breast, the midline, and the sternal notch. A 3-member panel comprised of either health care professionals or patients then assessed the images. Significant differences were reported in the aesthetic outcome between each method of assessment.

Quantitative and objective measurements of breast ptosis have been designed based on ratios of distances between fiducial points manually identified in digitized/digital images of oblique and lateral clinical photographs (pre-operative). The new objective measures of ptosis showed encouraging levels of concordance with ratings made by experienced surgeons using a 4-point scale by Regnault (43). The objective measures were found to be robust to intra- and inter- observer variability in marking fiducial points, including identifications by "novice" observers. The variability in the objective measurements due to intra- and inter- observer variability in marking fiducial points was shown to be equivalent to less than one point on the subjective ptosis scale (44).

Photogrammetry has advantages over anthropometry. A photograph is more efficient and less intrusive for the patient. It is a permanent record from which it is possible to retrospectively make a variety of measurements. There is potential for more consistent, 
objective results by analyzing digital/digitized photographs on a computer. The disadvantages are that some anatomic landmarks may not be visible and the measurements cannot be obtained following the contours of the patient's body. Some studies have reported substantial intra- and inter- observer standard deviation for linear measurements on photographs, related primarily to the lack of consistency in the manual identification of anatomic landmarks (40). Consistent guidelines for standard photography are critical to obtaining reproducible assessment of aesthetic outcomes by photogrammetry (45-49).

There are commercial software systems for working with digital/digitized photographs in plastic surgery, such as Nautilus Plastic DesignerTM (NauSoft LLC, St. Louis, MO), Mirror $^{\mathrm{TM}}$ software (Canfield Clinical Systems, Fairfield, NJ), and iMARS ${ }^{\mathrm{TM}}$ software (iMARS Medical Office Management Systems). However, it should be noted that most products are focused on data management rather than analysis. Some such systems will allow the surgeon to simulate or morph the postoperative result in an artistic manner that is not really representative of the actual surgical outcome.

\section{Three-dimensional Imaging}

Several technologies such stereophotogrammetry, laser scanning, three-dimensional digital photography, and light digitizers can be used to create three-dimensional (3D) images (Figure 2, Table 4) (50). The use of 3D imaging is well documented in craniofacial and facial plastic surgery (50-55). For breast surgery, 3D imaging permits evaluation of differences in volume, surface area, shape, size, contour, and symmetry (51,56-59). A single 3D image yields more information regarding breast appearance than multiple conventional photographs including data regarding some elements of the breast appearance, such as volume, that are not available from two-dimensional images (7). Assessment of the degree of soft-tissue edema following surgery is another important application of 3D imaging $(58,60)$.

Breast volume is an extremely useful parameter for the correction of breast asymmetry in breast reconstruction. For example, for a patient seeking delayed unilateral reconstruction, the calculated volume of the contra-lateral breast could facilitate the selection of implant/ tissue volume that would provide improved symmetry. Many methods have been described to determine breast volume: water displacement, The Grossman-Roudner device, thermoplastic casting, biosterometric analysis, and radiographic techniques (24, 61-69). Most of them are inaccurate, time-intensive, or expensive. Semi-automated (70) or automated (71) volume calculations from 3D data overcome those limitations. Another advantage is that point-to-point measurements can be made along the breast surface rather than by line-of-sight. Moreover, it is possible to rotate the subject on the computer screen to see not only the front and side views, but also at any angle in between (72).

Galdino et al. analyzed 3D images of over 50 patients who underwent breast reconstruction (58). They used the images to preoperatively estimate the expander and implant volumes, decide between TRAM versus DIEP surgeries, and to postoperatively assess breast asymmetry. Three-dimensional imaging of contralateral breast volume has been used to estimate volume requirements for breast reconstruction (7). The accuracy and reproducibility of 3D analysis was tested by comparing breast volumes calculated from 3D images to actual volumes measured from mastectomy specimens by water displacement. Difficulty was experienced in the analysis of very ptotic breasts, with a tendency to under calculate breast volume. Variability in volume analysis was attributed to difficulties in consistently identifying breast boundaries. Three-dimensional imaging may also be useful for evaluating longitudinal changes by superimposing images over time (60). 
Commercially available 3D imaging systems for plastic surgeons include features such as morphing operations and a broad range of art tools for simulation of cosmetic alterations on images. Some of the popular software systems include 3dMD Breast Analysis ${ }^{\mathrm{TM}}$ (3-Q, Inc., Atlanta, GA) and 3D Surgeons (Genex Technologies Inc., Kensington, MD). However, as is the case for systems for analyzing 2D images, some systems for 3D imaging will allow the surgeon to simulate or morph the postoperative result in an artistic manner that is not really representative of the actual surgical outcome.

Three-dimensional imaging has tremendous potential for analysis of breast appearance. The technique does have limitations, particularly for women with large, ptotic breasts and patient positional changes do influence measurements. Nevertheless, 3D systems may offer the most accurate means to quantify numerous elements of breast appearance and evaluate changes over time $(58,73)$. Further development of this technology might yield a variety of useful clinical tools to aid surgical planning, patient decision making, and outcomes analysis $(7,72,73)$.

\section{CONCLUSIONS}

The contemporary goals of breast cancer treatment are not limited to cure but include maximizing quality of life. All breast cancer treatment has the potential to adversely affect breast appearance and cause morbidity due to deformity. Developing objective, quantifiable methods to assess breast appearance is important to understand the impact of deformity on patient quality of life, guide selection of current treatments, and make rational treatment advances.

Aesthetics will always be an elusive outcome due to the variability of culture, ethnicity, and personal preferences. Nevertheless, the physical elements that define breast appearance do permit objective evaluation and may serve as tools to gain better control over aesthetic outcomes. Developing tools to more objectively assess the anatomic components of breast appearance will contribute to better evaluation of aesthetics. More research is needed to develop an evaluation method with high reliability and reproducibility that is also practical. A detailed subjective qualitative scale with standardized terminology would improve communication between reconstructive surgeons and radiation oncologists. Quantitative calculations based on standardized digital/digitized two-dimensional photography could be a reliable and reproducible approach that takes advantage of existing, easy access technology. Three-dimensional imaging has even greater potential, though more substantial development is needed.

In the absence of an absolute "gold standard", a comparative analysis of quantitative aesthetic outcome assessment by medical professionals, assessment by patients, and degree of patient satisfaction would be useful for identifying factors that influence a woman's quality of life after breast cancer treatment and rehabilitation and as a check of the appropriateness of new assessment measures. Highly reliable outcome scales would allow more meaningful comparison of results and cost-effectiveness among surgical techniques. They would be applicable not only to breast cancer treatment but to all forms of plastic surgery of the breast.

\section{Acknowledgments}

The authors would like to thank Kelly N. Forsythe and Nick Markey for bibliographic data entry. This work was supported in part by a grant from The University of Texas at Austin Office of the Vice President for Research and grant number 1 R21 CA109040 - 01A1 from National Cancer Institute. We also thank Fatima Merchant for helpful discussions. 


\section{REFERENCES}

1. Bostwick, J, III. Plastic and reconstructive breast surgery. 2 Ed.. Quality Medical Publishing, Inc.; St. Louis, Missouri: 1999.

2. Evans GR, Kroll SS. Choice of technique for reconstruction. Clin. Plast. Surg. 1998; 25:311. [PubMed: 9627789]

3. Morrow M, Strom EA, Bassett LW, et al. Standard for breast conservation therapy in the management of invasive breast carcinoma. CA Cancer J. Clin. 2002; 52:277. [PubMed: 12363326]

4. Apantaku LM. Breast conserving surgery for breast cancer. Am. Fam. Phy. 2002; 66:2271.

5. Goldwyn, RM. Plastic and reconstructive surgery of the breast. Little Brown; Boston: 1976.

6. Al-Ghazal SK, Fallowfield L, Blamey RW. Does cosmetic outcome from treatment of primary breast cancer influence psychosocial morbidity? Eu. J. Surg. Oncol. 1999; $25: 571$.

7. Kovacs L, Zimmermann A, Papadopulos NA, et al. Re: Factors determining shape and symmetry in immediate breast reconstruction. Ann. Plast. Surg. 2004; 53:192. [PubMed: 15269594]

8. Sarwer DB. Differences in breast shape preferences between plastic surgeons and patients seeking breast augmentation [Discussion]. Plast. Reconstr. Surg. 2003

9. Hsia HC, Thomson JG. Differences in breast shape preferences between plastic surgeons and patients seeking breast augmentation. Plast. Reconstr. Surg. 2003; 112:312. [PubMed: 12832909]

10. Sarwer DB, Cash TF, Magee L, et al. Female college students and cosmetic surgery: an investigation of experiences, attitudes, and body image. Plast. Reconstr. Surg. 2005; 115:931. [PubMed: 15731697]

11. von Soet T, Kvalem IL, Skolleborg KC, et al. Psychosocial factors predicting the motivation to undergo cosmetic surgery. Plast. Reconstr. Surg. 2006; 117:51. [PubMed: 16404248]

12. Sarwer DB. Psychosocial factors predicting the motivation to undergo cosmetic surgery [Discussion]. Plast. Reconstr. Surg. 2006; 117:63.

13. Andrade WN, Semple JL. Patient self-assessment of the cosmetic results of breast reconstruction. Plast. Reconstr. Surg. 2006; 117:44. [PubMed: 16404246]

14. Sarwer DB. Patient self-assessment of the cosmetic results of breast reconstruction [Discussion] Plast. Reconstr. Surg. 2006; 117:48.

15. Sarwer, DB.; Pruzinsky, T.; Cash, TF., et al. Psychological aspects of reconstructive and cosmetic plastic surgery: clinical, empirical, and ethical perspectives/editors. Lippincott Williams \& Wilkins; Philadelphia: 2005.

16. Edsander-Nord A, Brandberg Y, Wickman M. Quality of life, patients' satisfaction, and aesthetic outcome after pedicled or free TRAM flap breast surgery. Plast. Reconstr. Surg. 2001; 107:1142 [PubMed: 11373553]

17. Asko-Seljavaara S. Quality of life, patients' satisfaction, and aesthetic outcome after pedicled or free TRAM flap breast surgery [discussion]. Plast, Reconstr. Surg. 2000; 107:1154.

18. Pezner RD, Lipsett JA, Vora NL, et al. Limited usefulness of observer-based cosmesis scales employed to evaluate patients treated conservatively for breast cancer. Int. J. Rad. Onc. Bio. Phy. 1985; 11:1117.

19. Lowery JC, Wilkins EG, Kuzon WM, et al. Evaluations of aesthetic results in breast reconstruction: an analysis of reliability. Ann. Plast. Surg. 1996; 36:601. [PubMed: 8792969]

20. Sneeuw KC, Aaronson NK, Yarnold JR, et al. Cosmetic and functional outcomes of breast conserving treatment for early stage breast cancer. 1. Comparison of patients' ratings, observers' ratings, and objective assessments. Radiother. Oncol. 1992; 25:153. [PubMed: 1470691]

21. Boyages J, Barraclough B, Middledorp J, et al. Early breast cancer: cosmetic and functional results after treatment by conservative techniques. Aus. New Zealand J. Surg. 1988; 58:111.

22. Clarke D, Martinez A, Cox RS. Analysis of cosmetic results and complications in patients with stage I and II breast cancer treated by biopsy and irradiation. Int. J. Rad. Oncol. Biol. Phy. 1983; 9:1807.

23. Barterlink H, van Dam F, van Dogen J. Psychological effects of breast conserving therapy in comparison with radical mastectomy. Int. J. Rad. Oncol. Biol. Phy. 1985; 11:381. 
24. Cohen M, Evanoff B, George LT, et al. A subjective rating scale for evaluating the appearance outcome of autologous breast reconstruction. Plast. Reconstr. Surg. 2005; 116:440. [PubMed: 16079671]

25. Penn J. Breast Reduction. Br. J. Plast. Surg. 1955; 7:357. [PubMed: 13230442]

26. Smith DJ Jr. Palin WE Jr. Katch VL, et al. Breast volume and anthropomorphic measurements: normal values. Plast. Reconstr. Surg. 1986; 78:331. [PubMed: 3737757]

27. Smith DJ Jr. Palin WE Jr. Katch V, et al. Surgical treatment of congenital breast asymmetry. Ann. Plast Surg. 1986; 17:92. [PubMed: 3273092]

28. Westreich M. Anthropomorphic breast measurement: protocol and results in 50 women with aesthetically perfect breasts and clinical application. Plast. Reconstr. Surg. 1997; 100:468. [PubMed: 9252618]

29. Tsouskas LI, Fentiman IS. Breast compliance: a new method for evaluation of cosmetic outcome after conservative treatment of early breast cancer. Breast Cancer Res. Treat. 1990; 15:185. [PubMed: 2372571]

30. Stark B, Olivari N. Breast asymmetry: an objective analysis of postoperative results. Eu. J. Plast. Surg. 1991; 14:173.

31. Kuzbari R, Deutinger M, Todoroff BP, et al. Surgical treatment of developmental asymmetry of the breast. Long term results. Scand. J. Plast. Reconstr. Surg. Hand Surg. 1993; 27:203. [PubMed: 8272771]

32. Hauben DJ, Adler N, Silfen R, et al. Breast-areola-nipple proportion. Ann. Plast. Surg. 2003; 50:510. [PubMed: 12792541]

33. Al-Ghazal SK, Blamey RW, Stewart J, et al. The cosmetic outcome in early breast cancer treated with breast conservation. Eu. J. Surg. Oncol. 1999; 25:566.

34. Malata CM, McIntosh SA, Purushotham AD. Immediate breast reconstruction after mastectomy for cancer. Br. J. Surg. 2000; 87:1455. [PubMed: 11091232]

35. Christie DR, O'brien MY, Christie JA. A comparison of methods of cosmetic assessment in breast conservation treatment. Breast. 1996; 5:358.

36. Eadie C, Herd A, Stallard S. An investigation into digital imaging in assessing cosmetic outcome after breast surgery. J. Audiovisual Media Med. 2000; 23:12.

37. Brown ME, Semple J, Neligan P. Variables affecting symmetry of the nipple-areola complex. Plast. Reconstr. Surg. 1995; 96:846. [PubMed: 7652058]

38. Van Limbergen E, Rijnders A, van der Schueren E, et al. Cosmetic evaluation of breast conserving treatment for mammary cancer. 2. A quantitative analysis of the influence of radiation dose, fractionation schedules and surgical treatment techniques on cosmetic results. Radiother. Oncol. 1989; 16:253. [PubMed: 2616812]

39. Van Limbergen E, van der Schueren E, Van Tongelen K. Cosmetic evaluation of breast conserving treatment for mammary cancer. 1. Proposal of a quantitative scoring system. Radiother. Oncol. 1989; 16:159. [PubMed: 2587807]

40. Vrieling C, Collette L, Bartelink E, et al. Validation of the methods of cosmetic assessment after breast-conserving therapy in the EORTC "boost versus no boost" trial. EORTC radiotherapy and breast cancer cooperative groups. european organization for research and treatment of cancer. Int. J. Rad. Onc. Bio. Phy. 1999; 45:667.

41. Pezner RD, Patterson MP, Hill LR, et al. Breast retraction assessment: an objective evaluation of cosmetic results of patients treated conservatively for breast cancer. Int. J. Rad. Oncol. Bio. Phy. $1985 ; 11: 575$.

42. Sacchini V, Luini A, Tana S, et al. Quantitative and qualitative cosmetic evaluation after conservative treatment for breast cancer. Eu. J. Cancer. 1991; 27:1395.

43. Regnault P. Breast ptosis. definition and treatment. Clin. Plast Surg. 1976; 3:193. [PubMed: 1261176]

44. Kim MS, Reece GP, Miller MJ, et al. Objective assessment of aesthetic outcomes of breast cancer treatment: measuring ptosis from clinical photographs. Comp. Biol. Med. 2005 in press.

45. Yavuzer R, Smirnes S, Jackson IT. Guidelines for standard photography in plastic surgery. Plast. Reconstr. Surg. 2001; 46:293. 
46. Zarem HA. Standards of Photography. Plast. Reconstr. Surg. 74:1984.

47. Photographic Standards in Plastic Surgery. Plastic Surgery Educaton Foundation Education Tecnologies Committee; 2000.

48. DiBernardo BE, Adams RL, Krause J, et al. Photographic Standards in Plastic Surgery. Plast. Reconstr. Surg. 1998; 102:559. [PubMed: 9703100]

49. Ellenbogen RE, Jankauskas SJ, Collini FJ. Achieving standardized potographs in aesthetic surgery. Plast. Reconstr. Surg. 1989; 86:955. [PubMed: 2236321]

50. Honrado CP, Larrabee WFJ. Update in three-dimensional imaging in facial plastic surgery. Cur. Opi. Otolaryngol Head Neck Surg. 2004; 12:327.

51. O'Grady KF, Antonyshyn OM. Facial Asymmetry: Three-Dimensional Analysis Using Laser Surface Scanning. Plast. Reconstr. Surg. 1999; 104:928. [PubMed: 10654730]

52. Da Silveira AC, Daw JLJ, Kusnoto B, et al. Craniofacial applications of three-dimensional laser surface scanning. J. Craniofacial Surg. 2003; 14:449.

53. Nkenke E, Langer A, Laboureux X, et al. Validation of in vivo assessment of facial soft-tissue volume changes and clinical application in midfacial distraction: a technical report. Plast. Reconstr. Surg. 2003; 112:367. [PubMed: 12900593]

54. Ferrario VF, Sforza C, Dellavia C, et al. A quantitative three-dimensional assessment of soft tissue facial asymmetry of cleft lip and palate adult patients. J. Craniofacial Surg. 2003; 14:739.

55. Samson L. Three-Dimensional Photography and Its Application to Facial Plastic Surgery. Arch. facial plast. surg. 2004; 6:410. [PubMed: 15545536]

56. Boot JC, Naftel AJ, Ramli AR. Bodymap: an image processing system for the measurement of body surface profiles encountered in skin expansion surgery. Int. J. Bio-Med. Comp. 1992; 31:189.

57. Malata CM, Boot JC, Bradbury ET, et al. Congenital breast asymmetry: subjective and objective assessment. Br. J. Plast. Surg. 1994; 47:95. [PubMed: 8149066]

58. Galdino GM, Nahabedian M, Chiaramonte M, et al. Clinical applications of three-dimensional photography in breast surgery. Plast. Reconstr. Surg. 2002; 110:58. [PubMed: 12087232]

59. Loughry CW, Sheffer DB, Price TE Jr. et al. Breast volume measurement of 248 women using biostereometric analysis. Plast. Reconstr. Surg. 1987; 80:553. [PubMed: 3659165]

60. Losken A, Seify H, Denson DD, et al. Validating three-dimensional imaging of the breast. Ann. Plast. Surg. 2005; 54:471. [PubMed: 15838205]

61. Grossman AJ, Rounder LA. A simple means for accurate breast volume determination. Plast. Reconstr. Surg. 66:1980.

62. Sheffer DB, Price TE, Loughry CW, et al. Validity and reliability of biostereometric measurement of the human female breast. Ann. Biomed. Eng. 1986; 14:1. [PubMed: 3706852]

63. Loughry CW, Sheffer DB, Price TE Jr. et al. Breast volume measurement of 598 women using biostereometric analysis. Ann. Plast Surg. 1989; 22:380. [PubMed: 2729845]

64. Palin WEJ, von Fraunhofer JA, Smith DJJ. Measurement of breast volume: comparison of techniques. Plast. Reconstr. Surg. 1986; 77:253. [PubMed: 3945688]

65. Edsander-Nord A, Wickman M, Jurell G. Measurement of breast volume with thermoplastic casts. Scan. J. Plast. Reconstr. Surg. Hand Surg. 1996; 30:129.

66. Tezel E, Numanoglu A. Practical do-it-yourself device for accurate volume measurement of breast. Plast. Reconstr. Surg. 2000; 105:1019. [PubMed: 10724264]

67. Kalbhen CL, McGill JJ, Fendley PM, et al. Mammographic determination of breast volume: comparing different methods. Am. J. Roent. 1999; 173:1643.

68. Mineyev M, Kramer D, Kaufman L, et al. Measurement of breast implant volume with magnetic resonance imaging. Ann. Plast. Surg. 1995; 34:348. [PubMed: 7793778]

69. Edstrom LE, Robson MC, Wright JK. A method for the evaluation of minor degrees of breast asymmetry. Plast. Reconstr. Surg. 1977; 60:812. [PubMed: 918193]

70. Rigotti C, Ferrigno G, Aliverti A, et al. Surface scanning: an application to mammary surgery. J. Biomed. Optics. 1998; 3:161. 
71. Passalis, GT.; Theoharis, MM.; Kakadiaris, IA. Non-invasive automatic breast volume estimation for post-mastectomy breast reconstructive surgery.. Proc. 25th Ann. Int. Conf. IEEE Eng. Med. Biol. Soc. 2003.

72. Jacobs RA. Three-dimensional photography. Plast. Reconstr. Surg. 2001; 107:276. [PubMed: 11176640]

73. Nahabedian MY. Invited discussion : validating three-dimensional imaging of the breast. Ann. Plast. Surg. 2005; 54:477. 


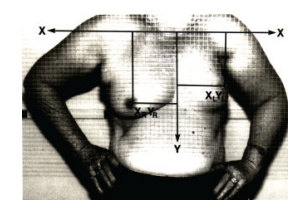

Figure 1.

Breast Retraction Assessment (BRA). AP view of the patient standing behind acrylic grid plate. $\mathrm{X}$ - and $\mathrm{Y}$-axes are marked on the photographs and distances between nipples are calculated using the grids for calculating BRA.

"Reprinted from Publication Pezner, R.D., et al., Breast retraction assessment: an objective evaluation of cosmetic results of patients treated conservatively for breast cancer.

International Journal of Radiation Oncology, Biology, Physics, 1985. 11(3): p. 575-8. with permission from Elsevier" 


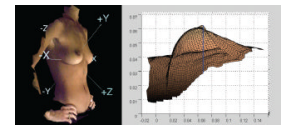

Figure 2.

Representative images illustration and measurement capabilities. Left image displayed laterally rotated image and co-ordinate axes. Right view displayed using the mesh mode and surface of the breast. Breast projection and volume enclosed between the base and the surface are quantitatively estimated. Reproduced images by 3dMDtorso Imaging System (3Q, Technologies Ltd., Atlanta, GA). 
Table 1

Subjective Assessments.

\begin{tabular}{|c|c|c|c|}
\hline Reference & Scale & Subject Population & Findings \\
\hline Pezner (18) & Two 4-point ordinal scales & $\begin{array}{l}14 \text { Photographs of BCT } \\
\text { patients }\end{array}$ & $\begin{array}{l}\text { Experienced observers had higher agreements than novice } \\
\text { observers. The scales showed low reliability }(\kappa=0.31) \text {. }\end{array}$ \\
\hline Lowery (19) & $\begin{array}{l}\text { 4-point, subscales (volume, } \\
\text { contour, inframammary } \\
\text { fold, scars), \& visual } \\
\text { analogue scales }\end{array}$ & $\begin{array}{l}50 \text { photographs of BRC } \\
\text { patients }\end{array}$ & $\begin{array}{l}\text { Suggested explicit criteria and to separate various components of } \\
\text { the aesthetic result to improve the reliability of the assessment. } \\
\text { Low reliability was observed: four-point scale }(\kappa=0.31) \text {, visual } \\
\text { analogue scale }(\kappa=0.13-0.15) \text {, subscales }(\kappa=0.19-0.63) \text {. }\end{array}$ \\
\hline Sneeuw (20) & $\begin{array}{l}\text { 4-point scale with subscales } \\
\text { (scar, size, shape, color, } \\
\text { firmness) }\end{array}$ & $\begin{array}{l}76 \text { Photograph of BCT } \\
\text { patients }\end{array}$ & $\begin{array}{l}\text { Reported higher intra-rater agreement between the nurse and the } \\
\text { oncologist }(\kappa=0.64) \text { but lower inter-rater agreements between } \\
\text { ratings by patients and clinical observers }(\kappa<0.10) \text { using global } \\
\text { 4-point scale. Subscales of } 4 \text {-point scale showed low to moderate } \\
\text { reliabilities }(\kappa=0.24-0.40) \text {. }\end{array}$ \\
\hline Cohen (24) & $\begin{array}{l}\text { Questionnaire on breast } \\
\text { aesthetics with 5-point } \\
\text { scale }\end{array}$ & $\begin{array}{l}36 \text { photographs of BRC } \\
\text { patients }\end{array}$ & $\begin{array}{l}\text { Reported better internal consistency }(\alpha=0.92) \text { and more } \\
\text { reliability of ratings }(\kappa=0.57-0.88) \text { by patients evaluating their } \\
\text { own results; Ratings by surgeons were not as internally consistent } \\
\text { (Chronbach } \alpha=0.74-0.89) \text { and reproducible }(\kappa=0.0-0.39) \text { as } \\
\text { patients' ratings. }\end{array}$ \\
\hline
\end{tabular}


Table 2

Physical Measurements.

\begin{tabular}{|c|c|c|}
\hline Reference & Subject Population & Findings \\
\hline Penn (25) & 20 aesthetically Normal breasts & Linear measurements between fiducial points were compared and tabulated. \\
\hline Smith (26) & $\begin{array}{l}66 \text { patients with breast hypertrophy, } \\
\text { ptosis, or both }\end{array}$ & Symmetry data for right and left breasts are described. \\
\hline Smith (27) & 40 patients with breast asymmetry & $\begin{array}{l}\text { Weak correlation ( } r=0.05-0.35) \text { was reported for nipple position relative to } \\
\text { sternal notch, midline, and axilla in relation to subjective score. }\end{array}$ \\
\hline Westreich (28) & $\begin{array}{l}50 \text { women with aesthetically perfect } \\
\text { breasts }\end{array}$ & $\begin{array}{l}\text { Of } 22 \text { linear measurement performed, nine measurements were shown to have } \\
\text { significant correlation with breast volume (Pearson } r=0.459-0.592) \text {. }\end{array}$ \\
\hline Tsouskas (29) & $\begin{array}{l}151 \text { women ( } 100 \text { normal breasts and } 51 \\
\text { BCT patients) }\end{array}$ & The reliability of the measurement was not clear. \\
\hline Stark (30) & 72 women with asymmetrical breasts & $\begin{array}{l}\text { Breast symmetry was assessed by three linear measurements between fiducial } \\
\text { points and the overall result was compared with patient's own evaluation, but } \\
\text { the correlation between the measures and reproducibility was not statistically } \\
\text { analyzed. }\end{array}$ \\
\hline Hauben (32) & 37 women with normal breasts & $\begin{array}{l}\text { Reported correlation of patient characteristics (age, height, weight, BMI) and } \\
\text { breast proportions and significant positive correlations between age and areola- } \\
\text { breast proportion (Pearson } r=0.47 \text { ). }\end{array}$ \\
\hline
\end{tabular}


Table 3

Photographic Measurements.

\begin{tabular}{|c|c|c|c|c|}
\hline Reference & Method or Scale & Subject & Population & Findings \\
\hline Pezner (41) & $\begin{array}{l}\text { Breast Retraction } \\
\text { Assessment (BRA) }\end{array}$ & $\begin{array}{l}\text { Patient \& clear acrylic } \\
\text { grid and photographs }\end{array}$ & $\begin{array}{l}29 \text { Normal women } \\
\text { compared to } 27 \\
\text { BCT patients }\end{array}$ & $\begin{array}{l}\text { BRA was significantly greater for breast cancer } \\
\text { patients than for the control groups. BRA } \\
\text { calculations correlated with the size of } \\
\text { resection. }\end{array}$ \\
\hline $\begin{array}{l}\text { Van } \\
\text { Limbergen }(38, \\
39)\end{array}$ & $\begin{array}{l}\text { BRA and panel } \\
\text { scoring }\end{array}$ & AP Photographs & 142 BCT patients & $\begin{array}{l}\text { Significant correlations between BRA and the } \\
\text { subjective scores were found. Increased BRA } \\
\text { associated with poorer cosmetic outcome. } p= \\
0.0001: \text { s square test, Kendall Tau B and } \\
\text { Kendall Tau C }\end{array}$ \\
\hline Vrieling (40) & BRA and pBRA & AP Photographs & 647 patients & $\begin{array}{l}\text { Found a significant correlation between } p \text { BRA } \\
\text { and subjective assessment at a three-year } \\
\text { follow-up except for those with inferomedially } \\
\text { located tumors }(\rho=0.24-0.53) \text {. }\end{array}$ \\
\hline Sacchini (42) & $\begin{array}{l}4 \text { measures of } \\
\text { distances between } \\
\text { fiducial points }\end{array}$ & AP Digital images & 148 BCT patients & $\begin{array}{l}\text { A 3-member panel, comprised of either health } \\
\text { care professionals or patients, assessed the } \\
\text { images. Significant difference in the aesthetic } \\
\text { outcome among groups was reported. }\end{array}$ \\
\hline $\operatorname{Kim}(44)$ & $\begin{array}{l}\text { Ratios of distances } \\
\text { between fiducial } \\
\text { points }\end{array}$ & $\begin{array}{l}\text { digitized/digital } \\
\text { images of oblique and } \\
\text { lateral (pre-operative) }\end{array}$ & 52 BRC patients & $\begin{array}{l}\text { The variability in the objective measurements } \\
\text { due to intra- and inter- observer variability in } \\
\text { marking fiducial points was shown to be } \\
\text { equivalent to less than one point on the } \\
\text { subjective ptosis scale. }\end{array}$ \\
\hline
\end{tabular}


Table 4

Three-dimensional Imaging.

\begin{tabular}{cll}
\hline Reference & Test Population & Findings \\
Galdino (58) & $\begin{array}{l}\text { Over } 100 \text { patients of } 5 \text { types } \\
\text { of breast surgery }\end{array}$ & $\begin{array}{l}\text { Extremely large breasts need additional manual intervention to capture the image. Volume of } \\
\text { breasts with significant ptsosis can be overestimated (contrast with the observation by Losken } \\
(60))\end{array}$ \\
Kovacs (7) & 1 BRC patient & $\begin{array}{l}\text { Breast volume was easily calculated in the virtual models as done with thermoplastic casts. } \\
\text { Some technical limitations were observed }\end{array}$ \\
Losken (60) & 14 BRC patients & $\begin{array}{l}\text { Difficulty was experienced in the analysis of very ptotic breasts, with a tendency to under } \\
\text { calculate breast volume (contrast with the observation by Galdino (58)). Inherent difficulties in } \\
\text { consistently identifying breast boundaries were observed }\end{array}$ \\
\hline
\end{tabular}

